\title{
Erratum to: Trefftz polygonal finite element for linear elasticity: convergence, accuracy, and properties
}

Hirshikesh', S. Natarajan ${ }^{*} \mathbb{0}$, R. K. Annabattula', S. Bordas² and E. Atroshchenko ${ }^{3}$

*Correspondence: snatarajan@iitm.ac.in

${ }^{1}$ Department of Mechanical Engineering, Indian Institute of Technology-Madras,

Chennai, India

Full list of author information

is available at the end of the article

\section{Erratum to: Asia Pac J Comput Engin (2017) 4:3 DOI 10.1186/s40540-017-0020-3}

After publication of the article [1], it was noticed that the name of R. K. Annabattula was incorrectly displayed as A. K. Ratna Kumar. The corrected author list can be seen in this erratum and the original article has been updated to reflect this.

\section{Author details}

${ }^{1}$ Department of Mechanical Engineering, Indian Institute of Technology-Madras, Chennai, India. ${ }^{2}$ Faculte des Sciences, de la Technologie et de la Communication, University of Luxembourg, Luxembourg, Luxembourg. ${ }^{3}$ Department of Mechanical Engineering, University of Chile, Santiago, Chile.

The online version of the original article can be found under doi:10.1186/s40540-017-0020-3.

\section{Publisher's Note}

Springer Nature remains neutral with regard to jurisdictional claims in published maps and institutional affiliations.

Received: 16 June 2017 Accepted: 16 June 2017

Published online: 28 June 2017

Reference

1. Hirshikesh, Natarajan S, Annabattula RK, Bordas S, Atroshchenko E (2017) Trefftz polygonal finite element for linear elasticity: convergence, accuracy, and properties. Asia Pac J Comput Eng 4:3. doi:10.1186/540540-017-0020-3 